\title{
Reduction of the Cement Content by Incorporation of Fine Recycled Aggregates from Construction and Demolition Waste in Rendering Mortars
}

\author{
Sara Jesus $^{1}$, Cinthia Maia Pederneiras ${ }^{1}\left(\mathbb{D}\right.$, Catarina Brazão Farinha ${ }^{1}\left(\mathbb{C}\right.$, Jorge de Brito ${ }^{1, *} \mathbb{C}$ and Rosário Veiga $^{2} \mathbb{C}$ \\ 1 CERIS, Instituto Superior Técnico, University of Lisbon, Av. Rovisco Pais 1, 1049-001 Lisbon, Portugal; \\ sara.jesus@tecnico.ulisboa.pt (S.J.); cinthiamaia@tecnico.ulisboa.pt (C.M.P.); \\ catarina.brazao.farinha@ist.utl.pt (C.B.F.) \\ 2 National Laboratory for Civil Engineering, Building Finishes and Thermal Insulation Division, \\ Department of Building, Av. do Brasil 101, 1700-066 Lisbon, Portugal; rveiga@lnec.pt \\ * Correspondence: jb@civil.ist.utl.pt
}

check for updates

Citation: Jesus, S.; Maia Pederneiras, C.; Brazão Farinha, C.; de Brito, J.; Veiga, R. Reduction of the Cement Content by Incorporation of Fine Recycled Aggregates from Construction and Demolition Waste in Rendering Mortars. Infrastructures 2021, 6, 11. https://doi.org/10.3390/ infrastructures6010011

Received: 11 December 2020 Accepted: 14 January 2021 Published: 16 January 2021

Publisher's Note: MDPI stays neutral with regard to jurisdictional clai$\mathrm{ms}$ in published maps and institutional affiliations.

Copyright: (C) 2021 by the authors. Licensee MDPI, Basel, Switzerland. This article is an open access article distributed under the terms and conditions of the Creative Commons Attribution (CC BY) license (https:// creativecommons.org/licenses/by/ $4.0 /)$.

\begin{abstract}
The construction sector is responsible for one third of the total wastes produced in the EU. Finding solutions for the reuse or recycling of these wastes is one of the major environmental concerns of modern times. The replacement of sand or cement in specific construction materials, such as concrete or mortars, is a possible solution for these wastes' management. By using construction and demolition wastes in construction materials, namely on buildings, the cycle of circular economy is closed, increasing the life cycle of the wastes in the same sector. In this research, a reduction of cement content in rendering mortars is analysed. This reduction is achieved by a decrease of the cement/aggregate ratio simultaneously with the incorporation of very fine recycled aggregate from construction and demolition waste. Two recycled aggregates were studied: recycled concrete aggregate (RCA) and mixed recycled aggregate (MRA). The fresh and hardened state properties of the mortars were analysed. Several tests were carried out to evaluate the mortars' performance, such as mechanical strength tests, water absorption tests, drying tests and shrinkage. It was noticed that the incorporation of RCA led to a better behaviour than in the reference mortar, in terms of mechanical strengths and protection against water.
\end{abstract}

Keywords: render; eco-mortars; sustainability; waste management; low $\mathrm{CO}_{2}$ emissions

\section{Introduction}

Cement is the most used binder in the production of mortars and concrete. Cement manufacture produces over $5-7 \%$ of the world's total $\mathrm{CO}_{2}$ emissions [1]. Clinker production is responsible for half of these emissions. In order to search for strategies to reduce the energy consumption of the cement industry, studies have been developed to minimize the volume of cement. Replacing clinker with other supplementary cementitious materials, such as fly ash, slag, silica fume and pozzolans, has been applied. However, several studies investigated other approaches to reduce cement-related emissions.

Studies on the reduction of the cement content in mortars by changing the volumetric ratio from 1:4 (cement: aggregates) to 1:5 and 1:6 and incorporating fines wastes from ceramics, concrete, glass and sanitary ware were carried out by Silva et al. [2], Braga et al. [3], Oliveira et al. [4] and Farinha et al. [5], respectively. These authors analysed the incorporation of up to $10 \%$ [2], $15 \%$ [3] and $20 \%$ [4,5] of fine waste material. In general, the results showed that the incorporation of fine particles offsets the drawbacks of the lower cement content, i.e., the mortars with less cement and higher waste contents presented a better or similar behaviour relative to the equivalent mortar richer in cement (1:4).

Regarding fine recycled aggregates (FRA) from construction and demolition waste (including recycled concrete aggregates, recycled masonry aggregates and mixed recycled 
aggregates) incorporated in mortars, several studies have been published [6-9]. However, the incorporation of this type of waste replacing natural aggregates and reducing cement in rendering mortars has not been researched for rendering mortars. In this sense, and in order to provide an original and new contribution to the knowledge on the incorporation of wastes in render mortars, through an extensive experimental work, this research studies the use of two types of very fine recycled aggregate: recycled concrete aggregate (RCA) and mixed recycled aggregate (MRA).

The fine recycled aggregates were incorporated as a replacement of a similar volume of sand. Additionally, this study investigated mortars with lower cement content (1:5 and 1:6 cement: aggregate, in volume); a comparison was made of those mortars with others also at 1:5 and 1:6 with natural sand and also with a reference mortar at 1:4 (cement: natural sand). This last comparison also allows for assessing the ability of these wastes to withstand reduction of cement without loss of performance.

In the literature, the analysis of reduction of cement in rendering mortars, incorporating very fine recycled aggregates, was not found. Therefore, the main objective of this work is to investigate the feasibility of reducing the cement content as well as using recycled aggregate in order to analyse their potential filler effect, which can contribute to a better performance of the mortar using a different volumetric ratio with lower cement content. Three volumetric ratios were analysed: 1:4, 1:5 and 1:6. This study is a follow-up of a previous one, which intended to select the optimal replacement ratio of sand with FRA from CDW [10]. Thus, $15 \%$ of MRA and $20 \%$ of RCA were considered the best incorporation percentages for each FRA [10]. These modified mortars maintained or even improved the mortars' properties. Thus, these ratios were used to produce the modified mortars in this research, for each volumetric ratio. The fresh and hardened state properties of the mortars were evaluated.

\section{Experimental Programme}

\subsection{Materials}

Mortars were produced with Portland cement, silica sand and recycled aggregates from CDW. CEM II/B-L 32.5N was the binder used, from the Portuguese producer Secil. The natural aggregate come from the Tagus River and only particles below $2.38 \mathrm{~mm}$ were used. The recycled aggregates came from two Portuguese CDW recycling plants: RCDResíduos de Construção e Demolição SA (RCA) and SGR Ambiente (MRA) and only particles smaller than $149 \mu \mathrm{m}$ were used, obtained by sieving. The constituents' particle size distribution is presented in a previous research [10].

In a previous research [10], the characterization of the constituents was performed, namely in terms of particle size distribution, bulk density and wastes composition. RCA is composed mainly of cementitious waste (99.67\%) and MRA consists of $70.83 \%$ of cementitious waste, $17.34 \%$ of ceramics waste and $11.82 \%$ of other materials. According to the X-ray Fluorescence analysis, $\mathrm{CaO}$ is the main component of RCA (52.53\%). On the other hand, the main chemical component in the composition of $\mathrm{MRA}$ is $\mathrm{SiO}_{2}(55.27 \%)$.

The recycled aggregates were incorporated without any additional processing, with the purpose of preserving the properties inherent to the manufacturing process. MRA replaced natural aggregate at $15 \%$ by volume and RCA at $20 \%$, in both cases by volume.

Three different volumetric ratios were analysed in this research: 1:4, 1:5 and 1:6 (cement: aggregates). Nine mortars were produced: three without wastes (REF 1:4, REF 1:5 and REF 1:6), three with MRA waste (MRA 1:4, MRA 1:5 and MRA 1:6) and three with RCA waste (RCA 1:4, RCA 1:5 and RCA 1:6). The apparent bulk density of the constituents of the mortars produced is listed hereinafter: cement $1030 \mathrm{~kg} / \mathrm{m}^{3}$, natural sand $1471 \mathrm{~kg} / \mathrm{m}^{3}$, RCA $878 \mathrm{~kg} / \mathrm{m}^{3}$ and MRA $810 \mathrm{~kg} / \mathrm{m}^{3}$. The composition of the mortars mixes is presented in Table 1. 
Table 1. Composition of the mortar mixes $\left(\mathrm{kg} / \mathrm{m}^{3}\right)$.

\begin{tabular}{cccccc}
\hline \multirow{2}{*}{ Mortar } & Water & Cement & $\begin{array}{c}\text { Natural } \\
\text { Aggregate }\end{array}$ & \multicolumn{2}{c}{ Recycled Aggregate } \\
\cline { 5 - 6 } & & 205.9 & 1177.1 & - & RCA \\
REF 1:4 & 230 & 205.9 & 1010.1 & - & - \\
MRA 1:4 & 198 & 205.9 & 951.1 & 134.9 & 92.0 \\
RCA 1:4 & 198 & 171.6 & 1226.2 & - & - \\
REF 1:5 & 244 & 171.6 & 1052.1 & - & - \\
MRA 1:5 & 200 & 171.6 & 990.7 & 140.5 & - \\
RCA 1:5 & 207 & 147.1 & 1261.2 & - & - \\
REF 1:6 & 250 & 147.1 & 1082.1 & - & 98.5 \\
MRA 1:6 & 210 & 147.1 & 1019.0 & 144.5 & - \\
RCA 1:6 & 210 & & &
\end{tabular}

\subsection{Methods}

The standards and number of specimens of all tests performed are listed below. The properties determined in the fresh and hardened mortars tests were:

- Fresh state:

- Consistency of fresh mortar (by flow table)—EN 1015-3 [11]. Two samples per mortar.

- Air content of fresh mortar-EN 1015-7 [12]. Fresh mortar. Two samples per mortar.

- Bulk density of fresh mortar-EN 1015-6 [13]. Three samples per mortar.

- Hardened state:

Mechanical properties:

- Dry bulk density of hardened mortar-EN 1015-10 [14], at 28 and 90 days. Three $160 \times 40 \times 40\left(\mathrm{~mm}^{3}\right)$ prisms per mortar.

- Flexural and compressive strength of hardened mortar-EN 1015-11 [15], at 28 and 90 days. Three $160 \times 40 \times 40\left(\mathrm{~mm}^{3}\right)$ prisms per mortar.

- Dynamic modulus of elasticity of hardened mortar-EN 14146 [16], at 28 and 90 days. Three $160 \times 40 \times 40\left(\mathrm{~mm}^{3}\right)$ prisms per mortar. The modulus of elasticity by frequency of resonance is calculated by Equation (1). The length of the specimen is given by $L$, the fundamental resonance frequency corresponds to $F$, the bulk density is $\rho$ and the gravity's acceleration is $g$.

$$
M E_{F R}=\frac{4 x L^{2} \times F^{2} \times \rho \times 10^{-6}}{g}
$$

- $\quad$ Ultrasound pulse velocity of hardened mortar-EN 12504-4 [17], at 28 days. To measure this property, two methods were applied: direct and indirect. In the direct method, the electrodes are on opposite sides of the prisms and, in the indirect method, the electrodes are on the same surface of the prisms. Three $160 \times 40 \times 40\left(\mathrm{~mm}^{3}\right)$ prisms per mortar.

Physical properties:

- Water absorption by capillarity of hardened mortar-EN 1015-18 [18], at 28 days. Three $80 \times 40 \times 40\left(\mathrm{~mm}^{3}\right)$ semi-prisms per mortar.

- Drying-After the water absorption test, the semi-prisms were weighed until their mass stabilized, by water evaporation. The evaporated water is measured by the loss of mass of these specimens during the drying process test. Three $80 \times 40 \times 40\left(\mathrm{~mm}^{3}\right)$ semi-prisms per mortar.

- Open porosity-EN 1936 [19]. Three samples per mortar, resulting from the compressive strength test at 90 days. 
- Dimensional instability variation-Centre Scientifique et Technique du Bâtiment (CSTB)Cahier 2669-4 [20]. Three $160 \times 40 \times 40\left(\mathrm{~mm}^{3}\right)$ prisms per mortar.

- Magnifying glass observation-the broken specimens obtained from the compressive strength test at 90 days were observed using a magnifying glass.

- $\quad$ Susceptibility to cracking - this test consists in applying a layer of mortar $2 \mathrm{~cm}$ thick on a brick and observing the eventual advent of superficial micro-cracking by naked eye.

- Water vapour permeability of hardened mortar-EN 1015-19 [21]. Three cylinder specimens per mortar;

Durability properties:

- Durability evaluation based on the artificial accelerated ageing test-EN 1015-21 [22]. The artificial ageing process involves two series: heat-freeze cycle and humidity-freeze cycles. Eight cycles of each series are performed. For the heating process, the temperature is kept constant at $60 \pm 2{ }^{\circ} \mathrm{C}$ for $8 \mathrm{~h} \pm 15 \mathrm{~min}$. On the other hand, for the freezing procedure, the temperature is kept constant at $-15 \pm 1{ }^{\circ} \mathrm{C}$ for $15 \mathrm{~h} \pm 15 \mathrm{~min}$. For the humidity phase, the temperature is kept constant at $20 \pm 2{ }^{\circ} \mathrm{C}$ inside a chamber with sprinkling water for $8 \mathrm{~h} \pm 15 \mathrm{~min}$.

- Permeability to water under pressure-EN 1015-21 [22]. Three bricks with a layer of mortar $2 \mathrm{~cm}$ thick were used in this test.

- Adherence strength of hardened mortar-EN 1015-12 [23]. Three bricks with a layer of mortar $2 \mathrm{~cm}$ thick were used in this test. Each brick was tested three times.

The specimens were submitted to different curing conditions. With the exception of the susceptibility to cracking, dimensional variation and water vapour permeability tests, all the specimens of hardened state tests were submitted to a temperature of $20 \pm 2{ }^{\circ} \mathrm{C}$ and a relative humidity of $95 \pm 5 \%$ until 2 days of age. Afterwards they were demoulded and kept in the same temperature and humidity conditions until 7 days of age. Then, the relative humidity to which the specimens were submitted was reduced to $65 \pm 5 \%$ until testing.

In the susceptibility to cracking and dimensional variation tests, the specimens were maintained in their moulds until 2 days at a temperature of $23 \pm 2{ }^{\circ} \mathrm{C}$ and a relative humidity of $50 \pm 5 \%$. Afterwards the specimens were demoulded and kept in the same temperature and humidity conditions, during the testing period.

In the water vapour permeability test, the specimens, in the moulds, were submitted to a temperature of $23 \pm 2{ }^{\circ} \mathrm{C}$ and a relative humidity of $95 \pm 5 \%$ until 2 days. Afterwards the specimens were demoulded. Until the test was performed, they were maintained at the same temperature conditions and at a relative humidity of $50 \pm 5 \%$.

\section{Results and Analysis}

\subsection{Consistency}

The water/binder ratio was defined according to the mortars' workability. In render mortars, workability is an important characteristic since it allows the mortar to be properly applied over the substrate. In order to compare all mortars in terms of workability, a value of consistency by flow table with a range of $160 \pm 3 \mathrm{~mm}$ was defined. In Table 2, the results of this test are presented. It was noted that the reduction of volumetric ratio resulted in exudation of the mortars. Nevertheless, they were still workable and the consistency predefined was maintained. The reduction of cement increased the $\mathrm{w} / \mathrm{b}$ ratio required to achieve the same flow table value. REF 1:5 and REF 1:6 needed more water content for the same cement quantity than REF 1:4; this could be due to the increase of the specific surface area of the aggregates, which required more water to lubricate the constituents. 
Table 2. Consistency (by flow table) of the mortars tested.

\begin{tabular}{cccc}
\hline Mortar & $\begin{array}{c}\text { Consistency by Flow } \\
\text { Table }(\mathbf{m m})\end{array}$ & Water/Cement Ratio & $\begin{array}{c}\text { Bulk Density of } \\
\left.\text { Fresh Mortar (kg/m } \mathbf{m}^{\mathbf{3}}\right)\end{array}$ \\
\hline REF 1:4 & 159.5 & 1.12 & $1952 \pm 4$ \\
MRA 1:4 & 160.0 & 0.96 & $1858 \pm 9$ \\
RCA 1:4 & 158.0 & 0.96 & $1982 \pm 7$ \\
REF 1:5 & 162.0 & 1.42 & $1927 \pm 8$ \\
MRA 1:5 & 163.0 & 1.17 & $1884 \pm 13$ \\
RCA 1:5 & 162.5 & 1.20 & $1968 \pm 3$ \\
REF 1:6 & 159.0 & 1.70 & $1915 \pm 2$ \\
MRA 1:6 & 159.5 & 1.43 & $1845 \pm 17$ \\
RCA 1:6 & 163.0 & 1.43 & $1907 \pm 16$ \\
\hline
\end{tabular}

However, the incorporation of FRA (both RCA and MRA), for the same cement ratio, reduced the amount of water needed in the mortars due to a filler effect. Those particles filled voids between the constituents, instead of water. Modified mortars poorer in cement (MRA 1:5, MRA 1:6, RCA 1:5 and RCA 1:6) needed less water to maintain an adequate consistency relative to REF 1:5 and REF 1:6. However, this decrease was not enough to reduce the water/binder ratio compared to REF 1:4. Other authors found the same trend $[2-5]$.

\subsection{Air Content of Fresh Mortar}

The results of the air content test are presented in Table 3. All the reference mortars had a similar air content, regardless of the cement content. The incorporation of RCA and MRA led to a considerable increase in the air content of the mortars. MRA 1:5 increased $107 \%$ compared to the REF 1:4. This increase of the air content may be related to the shape of these particles. The waste materials used in this research were submitted to crushing processes, which led to a more angular shape and thus contribute to the trapping of air in mortars.

Table 3. Air content.

\begin{tabular}{cc}
\hline Mortar & Air Content (\%) \\
\hline REF 1:4 & $7.13 \pm 0.13$ \\
MRA 1:4 & $8.88 \pm 0.13$ \\
RCA 1:4 & $13.88 \pm 0.13$ \\
REF 1:5 & $7.63 \pm 0.13$ \\
MRA 1:5 & $14.75 \pm 0.00$ \\
REF 1:6 & $7.13 \pm 0.13$ \\
RCA 1:6 & $10.00 \pm 0.00$ \\
\hline
\end{tabular}

These results agree with those of Oliveira et al. [4]. These authors observed a trend of increasing air content with the incorporation of glass fines. On the other hand, Farinha et al. [5] observed a decrease in air content in a mortar with $20 \%$ of sanitary ware and a volumetric ratio of 1:6. This could be explained by a greater effect of the cement reduction than that of the incorporation of fines.

\subsection{Bulk Density in Fresh and Hardened State}

The bulk density of the mortars varies differently according to the type of recycled aggregates. The incorporation of fine RCA presented a slight increase in the bulk density, both in the fresh and the hardened state, due to a filler effect, which prevailed over that of the lower bulk density of the aggregates (Table 2). On the other hand, modified mortars with MRA had a decrease due to a lower bulk density of the fines, prevailing over the filler effect. 


\subsection{Flexural and Compressive Strength} and 2).

The flexural and compressive strengths were analysed at 28 and 90 days (Figures 1

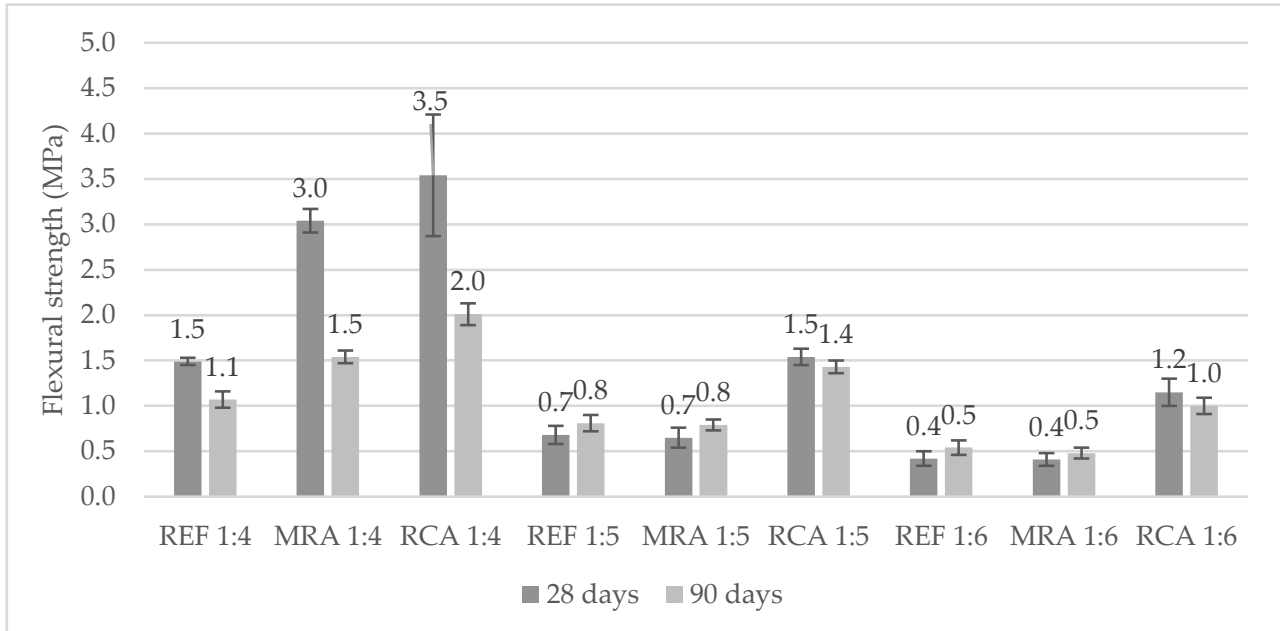

Figure 1. Flexural strength test results.

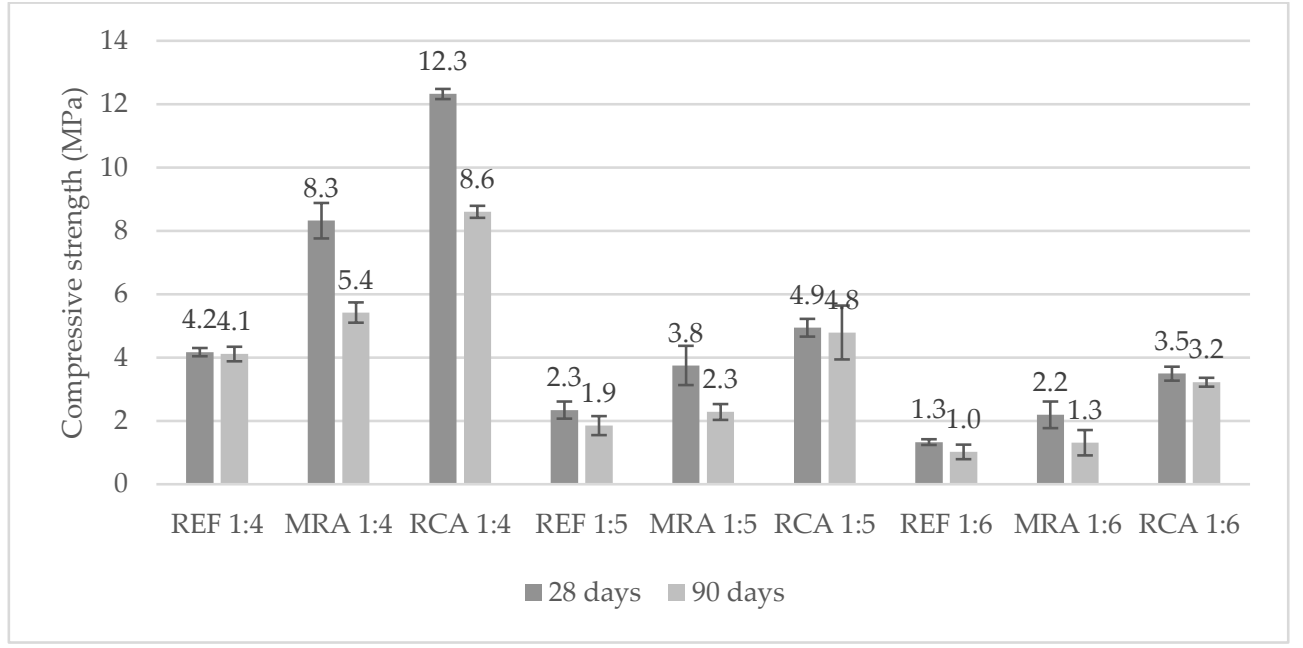

Figure 2. Compressive strength test results.

The reduction of cement reduces the mechanical strengths of the mortars. However, the incorporation of RCA may improve these properties. The modified mortar RCA 1:5 had an increase of $17 \%$ and $34 \%$ of the compressive and flexural strengths at 90 days, respectively, compared to REF 1:4. Nonetheless, RCA 1:6 presented a slight decrease, which did not considerably affect its performance. These improvements in the modified mortars with RCA could be explained by a filler effect and the non-hydrated cementitious particles in the waste that were hydrated by the mixing water.

The incorporation of MRA in poorer cement content mortars significantly reduces the mechanical strength compared to the reference mortar (REF 1:4). At 90 days, the modified mortar MRA 1:6 presented the lowest values of mechanical strengths: a decrease of $68 \%$ in compressive strength and $55 \%$ in flexural strength relative to REF 1:4. This decrease in mechanical strength led to believe that MRA does not have significant pozzolanic activity, despite brick dust particles in its composition.

In short, it was noticed that the modified mortars' behaviour with the reduction of cement content is influenced by the type of recycled aggregates incorporated. RCA 
incorporation led to an improvement while that of MRA reduced the mechanical strengths of the mortars.

A decrease in mechanical strengths from 28 days to 90 days was noticed. This may be justified by the appearance of internal micro-cracking in some specimens. Contrary to expectations, the decrease in strength was more significant in compressive strength than in flexural strength.

From the analysis of other studies, it was noticed that the incorporation of $15 \%$ of fine concrete aggregate with a cement content ratio of $1: 5$ led to an increase of $30 \%$ in compressive strength compared to the reference mortar (1:4 cement-aggregate ratio and $0 \%$ of FRA) [3]. The incorporation of sanitary ware with volumetric ratio of 1:5 led to an increase of $108 \%$ and $18 \%$ in compressive and flexural strength, respectively, compared to the control mortar (1:4 cement-aggregate ratio and $0 \%$ of FRA) [5]. The authors justified these increments with the combination of filler and pozzolanic effects. Silva et al. [2], Toledo et al. [24] and Hemraj et al. [25] replaced cement for fine ceramics waste and obtained a decrease in mechanical strengths for every ratio analysed.

From the results of this study, it can be seen that the reduction of the volumetric ratio of cement, together with the incorporation of fine recycled aggregates, may improve the mechanical behaviour of the mortars. This could be explained by the improvement of the interfacial transition zone between the cement matrix and the RA due to a more porous surface when compared to the natural aggregates. Chemical reactions could contribute to enhancing this mechanism as well, as also noticed by other authors, which used RCA. Braga et al. $[3,26]$ pinpointed the presence of unhydrated cement particles attached to the RCA. It is stressed that these particles may hydrate with the kneading water. Pozzolanic reactions between the $\mathrm{SiO}_{2}$ content and the hydrated cement's calcium hydroxide can also affect the performance of the RA in the mechanical behaviour of the mortars, as confirmed in previous studies by Silva et al. [2,27] and Farinha et al. [5]. Another factor that could enhance the mechanical strength of the modified mortars is the presence of fines, which suggests a filler effect. Angelim et al. [28], Braga et al. [3], Farinha et al. [5] and Oliveira et al. [4] stated that the fine particles filled the voids between the sand aggregates, which increases the compactness of the mortars and improves the mechanical strength.

\subsection{Dynamic Modulus of Elasticity}

The results of the dynamic modulus of elasticity by resonance frequency are presented in Table 4 and they were determined based on the standard EN 14146 [16]. The reduction of the binder content tends to decrease the modulus of elasticity of the modified mortars. In general, all the modified mortars presented a lower modulus of elasticity when compared to the control mortar, except for RCA 1:5, which had a slight increase of $1.2 \%$. For the volumetric ratio of 1:6, the amount of RCA incorporated was not sufficient to offset the effect of reducing the amount of cement. The lower content of cement may lead to an ineffective bond between aggregates, which contributes to a reduction in the mortar's compactness.

These results of the dynamic modulus of elasticity are in accordance with the mechanical strengths tests results, since the incorporation of recycled aggregate increased the flexural and compressive strengths of the mortars. The mortars' compactness also increased, which is indicated by a higher dynamic modulus of elasticity of the modified mortars than that of the reference mortar.

MRA led to a greater reduction in this property, for both volumetric ratios analysed. At 90 days, the modulus of elasticity of MRA was reduced by about 35\% and 55\% for the volumetric ratios of 1:5 and 1:6, respectively. This decrease of the dynamic modulus of elasticity can improve the absorption of deformations, avoiding/reducing cracking.

Farinha et al. [5], Braga et al. [3] and Oliveira et al. [4] obtained a similar trend, as the reduction of cement content reduced the modulus of elasticity, although with different results from the incorporation of very fine materials, which showed an increase in the modulus of elasticity from the volumetric ratio of $1: 4$ to $1: 5$ and 1:6. 
With the exception of MRA, all the modified mortars presented a decrease in modulus of elasticity values from 28 to 90 days. This difference is correlated to a possible internal micro-cracking of the specimens already mentioned in the mechanical strength tests analysis.

Table 4. Dynamic modulus of elasticity, ultrasound pulse velocity and open porosity.

\begin{tabular}{|c|c|c|c|c|c|c|}
\hline \multirow{2}{*}{ Mortar } & \multicolumn{2}{|c|}{ Dynamic Modulus of Elasticity (GPa) } & \multicolumn{2}{|c|}{ Ultrasound Pulse Velocity (m/s) } & \multirow{2}{*}{$\begin{array}{c}\text { Open Porosity } \\
(\%)\end{array}$} & \multirow{2}{*}{$\begin{array}{c}\text { Dry Bulk } \\
\text { Density }\left(\mathrm{kg} / \mathrm{m}^{3}\right)\end{array}$} \\
\hline & 28 Days & 90 Days & Direct Method & Indirect Method & & \\
\hline REF 1:4 & 11.0 & 10.4 & 2192 & 2345 & 22.1 & $1854 \pm 14$ \\
\hline MRA 1:4 & 11.9 & 11.7 & 2295 & 2259 & 22.4 & $1832 \pm 3$ \\
\hline RCA $1: 4$ & 15.3 & 15.3 & 2554 & 2443 & 19.8 & $1916 \pm 12$ \\
\hline REF 1:5 & 7.7 & 6.6 & 1927 & 2047 & 23.6 & $1789 \pm 9$ \\
\hline MRA 1:5 & 7.3 & 6.8 & 1871 & 1927 & 22.4 & $1837 \pm 8$ \\
\hline RCA $1: 5$ & 10.8 & 10.5 & 2205 & 2431 & 21.1 & $1796 \pm 4$ \\
\hline REF 1:6 & 5.5 & 5.0 & 1661 & 1773 & 24.6 & $1749 \pm 14$ \\
\hline MRA 1:6 & 4.1 & 4.7 & 1494 & 1585 & 23.5 & $1750 \pm 2$ \\
\hline RCA 1:6 & 9.1 & 7.8 & 2012 & 2041 & 22.3 & $1804 \pm 6$ \\
\hline
\end{tabular}

\subsection{Ultrasound Pulse Velocity}

Table 4 presents the results of the ultrasound pulse velocity test. In general, for both measuring methods (direct and indirect), the reduction of cement decreased the pulse velocity of the mortars. RCA 1:5 had a slight increase compared to REF 1:4. These results agree with those from the dynamic modulus of elasticity test, which evaluated the stiffness of the mortars.

\subsection{Water Absorption by Capillarity}

The results of the water absorption by capillarity test are presented in Table 5 .

Table 5. Water absorption by capillarity coefficient, water vapour permeability test results.

\begin{tabular}{ccc}
\hline Mortar & $\begin{array}{c}\text { Water Absorption by } \\
\text { Capillarity Coefficient } \\
\mathbf{k g} /\left(\mathbf{m}^{\mathbf{2}} \mathbf{m i n}^{\mathbf{0 . 5}}\right)\end{array}$ & $\begin{array}{c}\text { Water Vapour Permeability } \\
\mathbf{( n g / m ~ s ~ P a ) ~}\end{array}$ \\
\hline REF 1:4 & 0.87 & 17.52 \\
MRA 1:4 & 0.60 & 17.21 \\
RCA 1:4 & 0.50 & 15.67 \\
REF 1:5 & 1.61 & 24.64 \\
MRA 1:5 & 1.06 & 22.44 \\
RCA 1:5 & 0.81 & - \\
REF 1:6 & 1.93 & 27.63 \\
MRA 1:6 & 1.51 & - \\
RCA 1:6 & 0.97 & 22.06 \\
\hline
\end{tabular}

It was noted that the incorporation of RCA or MRA filler wastes reduced the capillary coefficient of the mortars, in comparison with the mortars without wastes and with the same volumetric ratio.

Comparing the modified mortars with poorer cement content with REF 1:4, it was observed that RCA 1:5 was the only one that reduced its capillary coefficient, with a value of $0.81 \mathrm{~kg} /\left(\mathrm{m}^{2} \cdot \mathrm{min}^{0.5}\right)$ corresponding to a reduction of $7 \%$ relative to REF 1:4. This reduction means that the filler effect of the waste prevailed over the reduction of the volumetric ratio. No other modified mortar was able to present improvements in comparison with REF 1:4. Regarding the incorporation of MRA, the reduction of the water absorption coefficient in relation to the REF 1:4 mortar is very significant, around $22 \%$ and $74 \%$, from $1: 4$ to $1: 5$ and $1: 6$, respectively. 


\subsection{Drying}

Figures 3 and 4 present the evaporation curves over time. From these curves, it is possible to evaluate the mortars' drying behaviour. The same specimens used to analyse the capillary test were submitted to this test. The reduction of cement interfered in the drying performance of the mortars. This reduction led to faster evaporation rates, which is related to the porosity of the mortars. The reduction of cement content increased the porosity of the mortars, improving their drying behaviour.

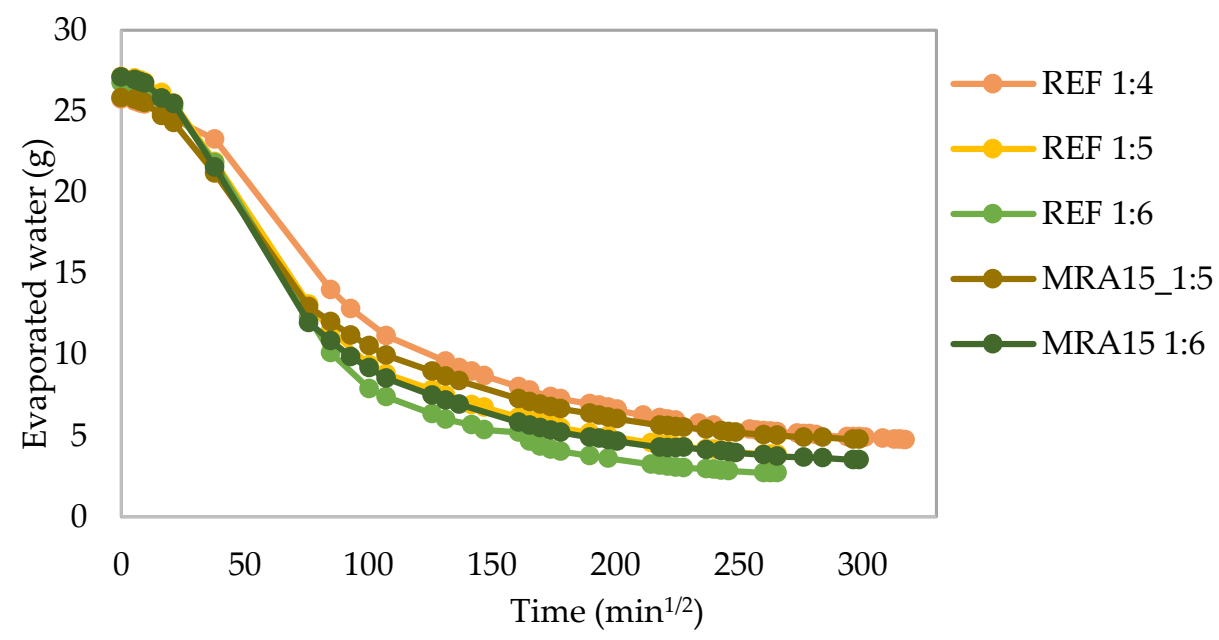

Figure 3. Drying curves of the mixed recycled aggregate (MRA) mortars.

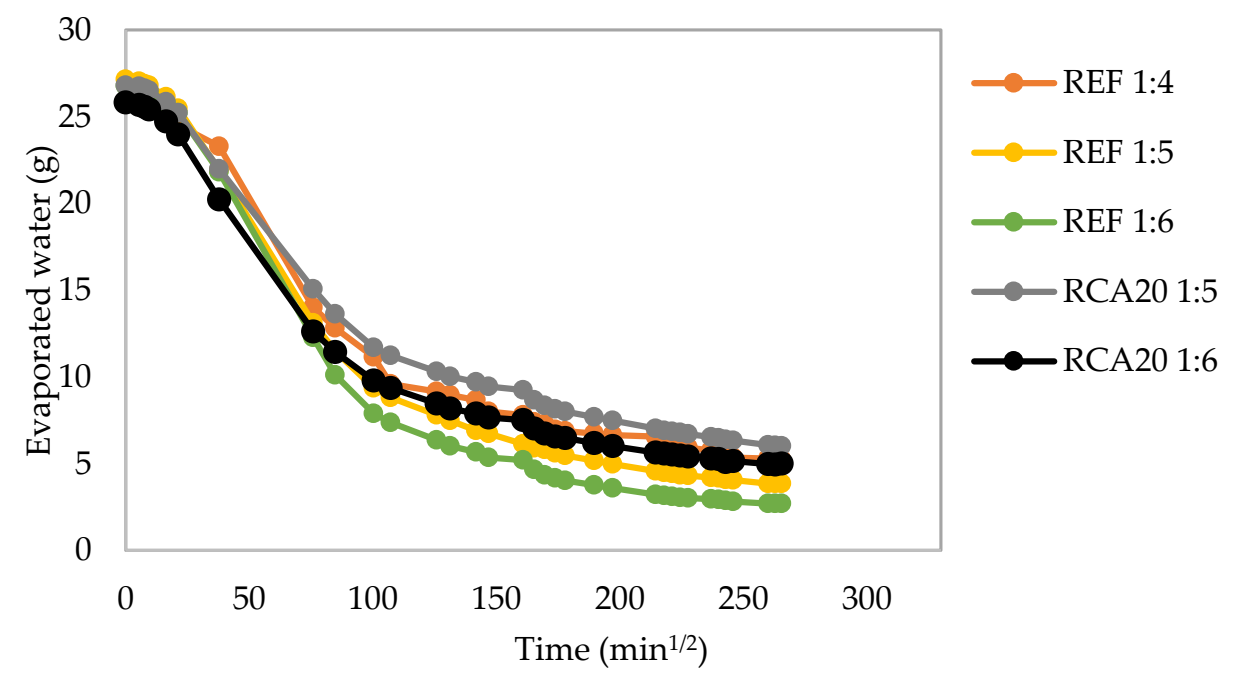

Figure 4. Drying curves of the recycled concrete aggregate (RCA) mortars.

Comparing the mortars with the same volumetric ratio, the incorporation of RA reduced the pores of the mortars (due to the filler effect). The modified mortars with FRA are more compact, which slightly hinders water evaporation.

Since RCA 1:5 presented a higher modulus of elasticity than REF 1:4 and also a lower open porosity (as presented forward) the increase of compactness of this mortar was confirmed. This led to more difficulty in water evaporation than in REF 1:4, as shown in Figure 4. On the other hand, Figure 3 shows that the incorporation of MRA may improve the drying performance, since the binder reduction prevailed over the filler effect.

Braga et al. [3], Oliveira et al. [4] and Farinha et al. [5] achieved similar conclusions, replacing part of the cement with concrete fines, glass and sanitary ware, respectively. 


\subsection{Open Porosity}

Table 4 presents the results of the open porosity test. The reduction of cement content is responsible for an increment of pores and consequently increases the open porosity of the mortars. This was observed not only in the reference mortars (REF 1:4, REF 1:5 and REF 1:6), but also the modified mortars with incorporation of FRA. However, as expected from the results of the other tests, RCA 1:5 had lower volume of pores, with a reduction of about $4.6 \%$ relative to REF 1:4. This can be explained by a filler effect, which prevailed over that of the binder content reduction and, therefore, there was a slight decrease in this property. However, RCA 1:6 followed the same trend of the other modified mortars.

Despite these results, for the cement-poor modified mortars, the percentage of interconnectable pores did not significantly change, i.e., they presented a performance similar to that of REF 1:4.

Mortars with incorporation of RCA followed a similar trend as found by Farinha et al. [5], i.e., a downward trend in open porosity as the cement content decreased to a volumetric ratio of 1:5.

\subsection{Dimensional Variation}

The results of the dimensional variation test are presented in Figure 5. The dimensional variation test was performed up to 90 days. However, it can be seen that the largest dimensional variation of the specimens occurred at an early age.

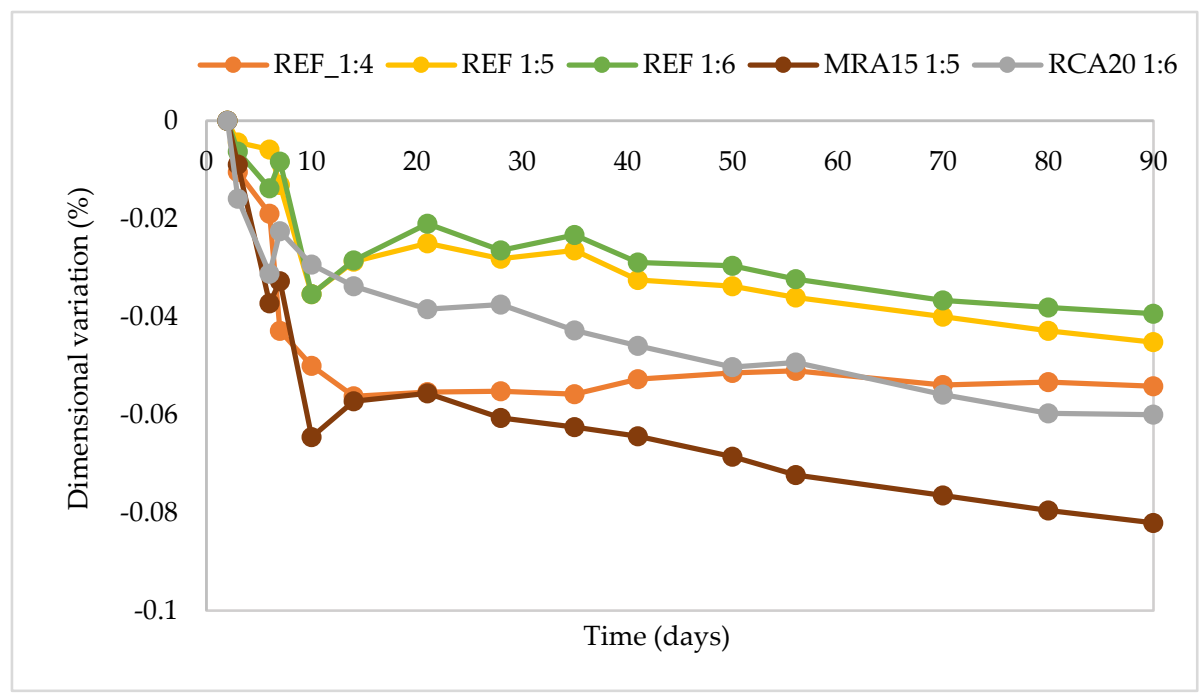

Figure 5. Dimensional variation of the mortars tested.

The reduction of cement content decreased the shrinkage. On the other hand, the incorporation of FRA increased the dimensional instability.

RCA 1:6 presented higher shrinkage than the REF 1:4 mortar, with an increment of about $11 \%$. On the contrary, the modified mortar MRA obtained the highest dimensional instability, about $52 \%$ higher than that of REF 1:4.

Braga et al. [3] and Oliveira et al. [4] reached similar conclusions. The incorporation of fines increased the mortars' shrinkage. This can be explained by a higher specific surface of the fines, which led to a higher surface tension due to the absorbed water film [29]. This caused an increase in mortar shrinkage. In addition, Braga et al. [3] also highlighted that the increase of shrinkage may be enhanced by residual non-hydrated cement of FRA.

\subsection{Magnifying Glass Observation}

An electronic magnifying glass was used to observe the specimens with magnification of $700 \%$ and the results are presented from Figures 6-9. The REF 1:6 and RCA 1:5 mortars presented an isolated micro-cracking pattern. However, in MRA mortars, a few cracks 
were also observed. Additionally, as expected, RCA 1:5 and REF 1:6 had a more compact matrix than the other mortars.

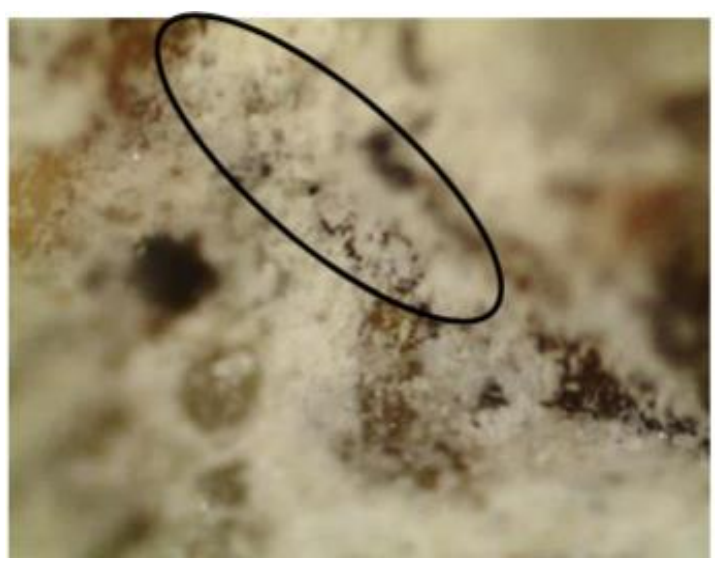

Figure 6. Micro-cracking observation in REF 1:6 mortar.

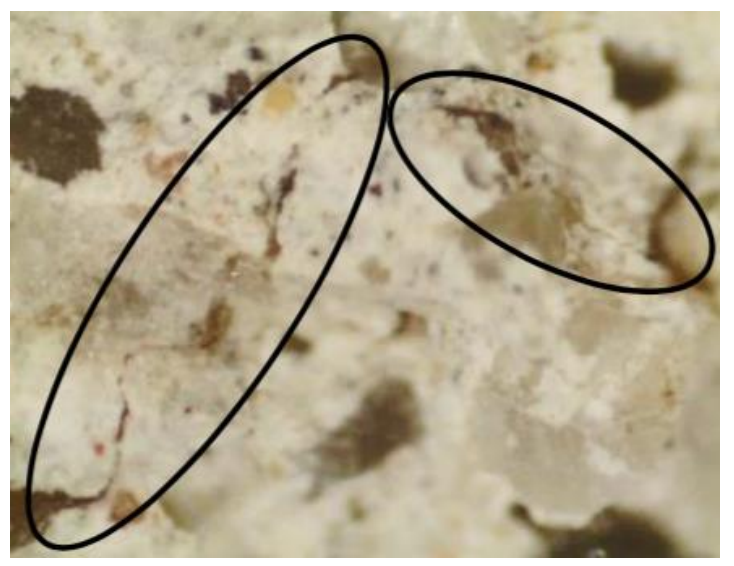

Figure 7. Micro-cracking observation in RCA15 1:4 mortar.

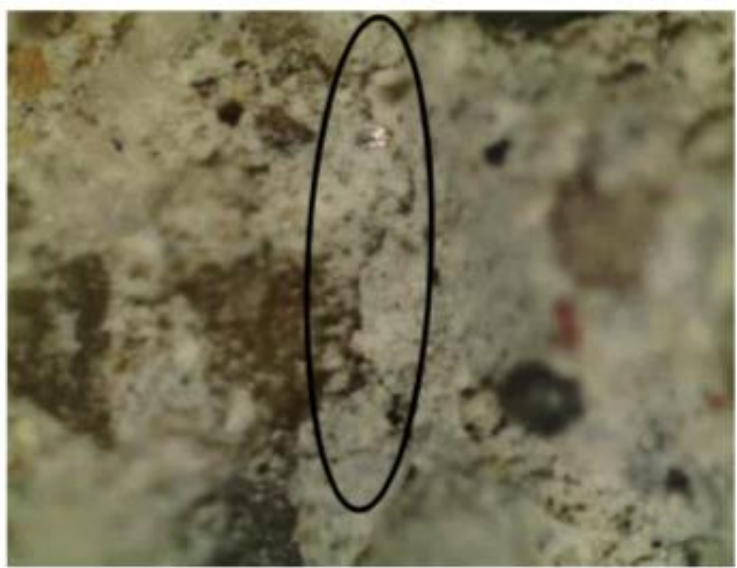

Figure 8. Micro-cracking observation in MRA15 1:5 mortar. 


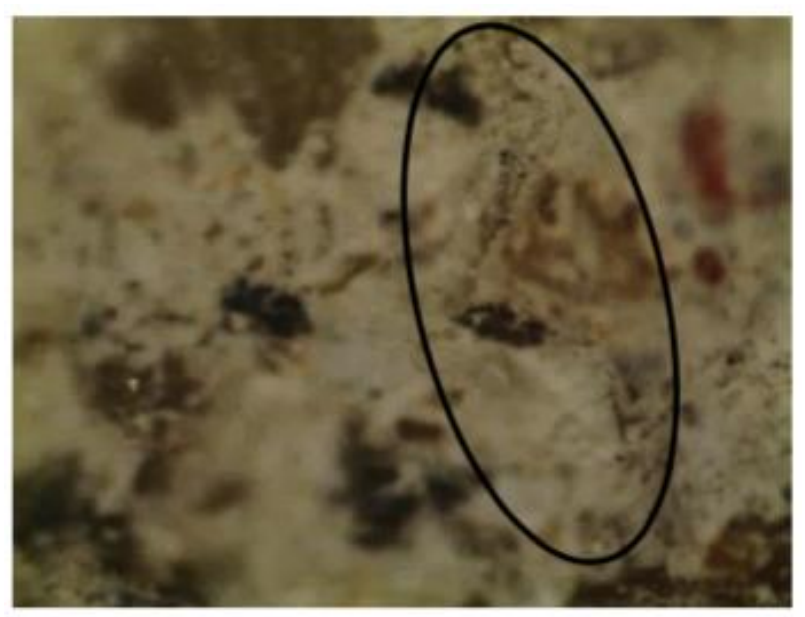

Figure 9. Micro-cracking observation in MRA15 1:6 mortar.

\subsection{Susceptibility to Cracking}

After 3 months of ocular observation, no micro-cracking was visible to the naked eye. In fact, the reduction of the binder offsets the incorporation of very fine FRA. Despite the increase in shrinkage, MRA had a modulus of elasticity more than $35 \%$ lower than that of REF 1:4. This means that the modified mortar may be able to absorb deformations without causing cracking.

Thus, it is possible to conclude, considering the application conditions used in the laboratory, which differ from those of application on site, that the mortars with reduced binder are unlikely to crack, with or without the incorporation of fine recycled aggregates. The results of Silva et al. [2], Braga et al. [3], Oliveira et al. [4] and Farinha et al. [5] followed the same trend.

\subsection{Water Vapour Permeability}

Rendering mortars should have a high water vapour permeability, which promotes drying of the coating as well as the exit of water vapour produced in the buildings' interior spaces, thus reducing problems inherent to the phenomenon of interior condensation [29].

The results of this test are presented in Table 5. The water vapour permeability increased by reducing the cement content. The incorporation of FRA, on the other side, decreased the water vapour permeability (comparing with the same volumetric ratio) of the modified mortars, due to the filler effect, which is consistent with the decrease found for open porosity. Compared with the REF 1:4, the MRA 1:5 and RCA 1:6 mortars presented higher water vapour permeability, meaning that the reduction of cement content reduced the negative impact of the filler introduction. In this sense, the MRA 1:5 and RCA 1:6 mortars are more permeable to water vapour, which is an advantage in rendering mortars.

Silva et al. [2] concluded that the mortars with a volumetric ratio of 1:6 and addition of $10 \%$ of fine ceramics may be more permeable, in a similar way to the results obtained in this study.

\subsection{Evaluation of Durability by the Artificial Accelerated Ageing Test}

Before and after artificial ageing, the visual aspect, permeability to water under pressure and adherence strength of the mortars were analysed.

\subsubsection{Visual Aspect}

No cracking was observed in any of the mortars studied. After artificial ageing, despite the degradation of the mortar's surface layer caused by its leaching, none of the renders showed visible cracks to the naked eye. 
Oliveira et al. [4] and Farinha et al. [5] also did not detect cracking or disintegration of the specimens. The authors studied the reduction of binder content and simultaneous incorporation of fine glass and sanitary ware.

\subsubsection{Permeability to Water under Pressure}

The results of the permeability to water under pressure test are presented in Table 6 .

The reduction of the cement content increased the permeability to water under pressure. On the other hand, the incorporation of very fine FRA may decrease the permeability to liquid water of the mortars, due to a filler effect. However, in this test, the incorporation of RCA 1:6 and MRA 1:5 was not sufficient to offset the effect of reducing the cement content. Therefore, the modified mortars were more porous than REF 1:4.

MRA 1:5 presented an increase of $119 \%$ and $46 \%$ compared to the REF 1:4 mortar, before and after ageing, respectively. Whereas RCA 1:6, even with lower amount of binder, had a similar permeability to MRA 1:5, at 28 days. However, after ageing, this is the mortar most affected by climate cycles, with a $43 \%$ increase in its permeability value.

Contrary to the results found in this research, Farinha et al. [5] found that, after artificial ageing, the hydration reactions improved performance of the mortars, with less cement content and simultaneous incorporation of $20 \%$ sanitary ware. The modified mortars studied by Farinha et al. [5] presented lower permeability to water under pressure. However, Oliveira et al. [4] obtained modified mortars with the incorporation of fine glass with a higher permeability than that of the reference mortar.

Table 6. Permeability to water under pressure and adherence strength test results.

\begin{tabular}{|c|c|c|c|c|c|c|}
\hline \multirow{3}{*}{ Mortar } & \multicolumn{2}{|c|}{$\begin{array}{l}\text { Permeability to Water under } \\
\text { Pressure }\left(\mathrm{mL} / \mathrm{cm}^{2}\right)\end{array}$} & \multicolumn{4}{|c|}{ Adherence Strength } \\
\hline & \multirow[b]{2}{*}{ Before Ageing } & \multirow[b]{2}{*}{ After Ageing } & \multicolumn{2}{|c|}{ Before Ageing } & \multicolumn{2}{|c|}{ After Ageing } \\
\hline & & & Strength (MPa) & $\begin{array}{l}\text { Fracture } \\
\text { Pattern }\end{array}$ & Strength (MPa) & $\begin{array}{c}\text { Fracture } \\
\text { Pattern }\end{array}$ \\
\hline REF 1:4 & 2.17 & 3.43 & 0.54 & $\mathrm{~A} / \mathrm{B}$ & 0.55 & $\mathrm{~B}$ \\
\hline MRA 1:4 & - & - & 0.66 & A & 0.64 & $\mathrm{~A} / \mathrm{B}$ \\
\hline RCA 1:4 & - & - & 0.87 & $\mathrm{~A} / \mathrm{C}$ & 0.66 & A \\
\hline REF 1:5 & 7.05 & 7.67 & 0.39 & B & 0.41 & B \\
\hline MRA 1:5 & 4.75 & 5.01 & 0.44 & B & 0.56 & $\mathrm{~A} / \mathrm{B}$ \\
\hline RCA 1:5 & - & - & - & - & - & - \\
\hline REF 1:6 & 8.52 & 8.93 & 0.29 & B & 0.27 & B \\
\hline MRA 1:6 & - & - & - & - & - & - \\
\hline RCA 1:6 & 4.49 & 6.63 & 0.66 & $\mathrm{~A} / \mathrm{B}$ & 0.63 & B \\
\hline
\end{tabular}

Note: Fracture pattern A-Adhesive fracture (in the interface mortar/substrate); Fracture pattern B-Cohesive fracture (in the mortar); Fracture pattern $\mathrm{C}$-Cohesive fracture (in the substrate).

\subsubsection{Adherence Strength}

The adherence strength was analysed before and after ageing and the results are presented in Table 6. The reduction of cement content directly affects the mechanical strength of the mortars, which had lower tensile strength. Additionally, the bond between the substrate and the render is compromised, as there is less water, cement and fines absorbed by the substrate, which weakens the adherence strength.

The incorporation of FRA resulted in an improvement of the adherence strength of the mortars. However, for MRA 1:5, this was not sufficient to offset the effect of reducing the cement content, i.e., there was a decrease of $20 \%$ in the adherence strength compared to REF 1:4.

Conversely, the incorporation of RCA 1:6 increased approximately 20\% compared to the REF 1:4 mortar. Therefore, it was concluded that the amount of RCA was enough to compensate the reduction of cement content. 
After accelerated ageing, there was an increase of about 27\% in MRA 1:5, due to the presence of water in the freeze-thaw cycles, which allowed the hydration of non-hydrated cement during the curing period. On the other hand, similarly to what happened for permeability to water under pressure, the cracking caused by ageing in RCA 1:6 led to a decrease in adherence strength. Nonetheless, the adherence strength is still higher than that of the reference mortar.

At 28 days, Silva et al. [2] and Braga et al. [3], by incorporating fine ceramic and fine concrete in mortars with reduced cement content, found an increase in the adherence strength, similarly to those of RCA 1:6. Whilst, Oliveira et al. [4] and Farinha et al. [5] observed a similar trend to that in RMA 1: 5, which consists in a decrease in the adherence capacity of these mortars, with the reduction of cement content. However, after accelerated ageing, all the modified mortars presented a better or very similar performance to that obtained by the reference mortar.

\section{Conclusions}

From the results obtained, it was concluded that mortars with cement reduction from 1:4 (cement: aggregates) down to $1: 6$ and simultaneous incorporation of $20 \%$ of RCA (in substitution of natural sand) have shown very satisfactory performance. These mortars exhibited improvements in most of the properties compared to the reference mortar, regarding mechanical strength and water absorption by capillarity. These enhancements are attributed to a filler effect and the presence of non-hydrated cement in the waste particles, which could prevail over the downside of cement content reduction. At 90 days, RCA 1:5 showed an increase of $17 \%$ and $34 \%$ in terms of the compressive and flexural strength, respectively, relative to the reference mortar at 1:4 volumetric ratio. After artificial ageing, RCA 1:6 obtained a decrease in adherence strength, due to cracking, although the strength was maintained greater than the REF 1:4's.

On the other hand, the incorporation of $15 \%$ of MRA did not achieve the same results, since the corresponding mortars that were poorer in cement had a more substantial loss in performance. Concerning the water absorption performance, MRA 1:6 obtained an increase of 74\% compared to REF 1:4. Regarding the flexural and compressive strengths, the decrease was about 55\% and 68\%, respectively. For MRA 1:5, it was found that after artificial ageing the adherence strength increased due to hydration of non-hydrated cement. The incorporation of MRA was not as successful as the incorporation of RCA, in mortars with reduced cement content.

Moreover, a mortar with much lower cement content (1:5 cement: aggregate compared to 1:4 cement: natural sand) achieved similar (in fact a little higher, but not significantly higher) mechanical characteristics, which is an important improvement. Therefore, the volumetric ratio of 1:5 achieved an optimal technical feasibility for non-structural mortars. Comparing the recycled aggregates, it was evidenced that the use of RCA overcame the results of MRA addition.

A relevant aspect is that the artificial ageing cycles performed do not prove a significant impact on the FRA mortars, affecting them on a similar way as the natural sand mortars.

Author Contributions: S.J. performed all the tests and established the correlation between all tests results. J.d.B. and R.V. supervised the research. C.M.P. wrote the manuscript and complemented the results analysis. C.B.F., J.d.B. and R.V. revised the manuscript. All authors have read and agreed to the published version of the manuscript.

Funding: This research was funded by Portuguese Foundation for Science and Technology (FCT), grant number PD/BD/135193/2017.

Institutional Review Board Statement: Not applicable.

Informed Consent Statement: Not applicable.

Data Availability Statement: The data presented in this study are available on request from the corresponding author. 
Acknowledgments: The authors acknowledge Instituto Superior Técnico, CERIS Research Centre, the National Laboratory for Civil Engineering and the Portuguese Foundation for Science and Technology for the support given to this research.

Conflicts of Interest: The authors declare no conflict of interest.

\section{References}

1. Shanks, W.; Dunant, C.F.; Drewniok, M.P.; Lupton, R.C.; Serrenho, A.; Allwood, J.M. How Much Cement Can We Do without? Lessons from Cement Material Flows in the UK. Resour. Conserv. Recycl. 2019, 141, 441-454. [CrossRef]

2. Silva, J.; de Brito, J.; Veiga, R. Fine ceramics replacing cement in mortars Partial replacement of cement with fine ceramics in rendering mortars. Mater. Struct. 2008, 41, 1333-1344. [CrossRef]

3. Braga, M.; de Brito, J.; Veiga, R. Reduction of the cement content in mortars made with fine concrete aggregates. Mater. Struct. 2014, 47, 171-182. [CrossRef]

4. Oliveira, R.; de Brito, J.; Veiga, R. Reduction of the cement content in rendering mortars with fi ne glass aggregates. J. Clean. Prod. 2015, 95, 75-88. [CrossRef]

5. Farinha, C.B.; de Brito, J.; Veiga, R.; Lucas, J. Reduction of cement content in renderings with fine sanitary ware aggregates. Mater. Struct. 2016, 49, 1605-1618. [CrossRef]

6. Silva, R.V.; de Brito, J.; Dhir, R.K. Performance of cementitious renderings and masonry mortars containing recycled aggregates from construction and demolition wastes. Constr. Build. Mater. 2016, 105, 400-415. [CrossRef]

7. Ledesma, E.F.; Jiménez, J.R.; Ayuso, J.; Fernández, J.M.; de Brito, J. Maximum feasible use of recycled sand from construction and demolition waste for eco-mortar production-Part-I: Ceramic masonry waste. J. Clean. Prod. 2015, 87, 692-706. [CrossRef]

8. Ferreira, R.L.S.; Anjos, M.A.S.; Nóbrega, A.K.C.; Pereira, J.E.S.; Ledesma, E.F. The role of powder content of the recycled aggregates of CDW in the behaviour of rendering mortars. Constr. Build. Mater. 2019, 208, 601-612. [CrossRef]

9. Roque, S.; Pederneiras, C.M.; Farinha, C.B.; de Brito, J.; Veiga, R. Concrete-based and mixed waste aggregates in rendering mortars. Materials 2020, 13, 1976. [CrossRef] [PubMed]

10. Jesus, S.; Maia, C.; Brazão, C.; de Brito, J.; Veiga, R. Rendering mortars with incorporation of very fine aggregates from construction and demolition waste. Constr. Build. Mater. 2019, 229, 116844. [CrossRef]

11. EN 1015-3. Methods of Test for Mortar for Masonry-Part 3: Determination of Consistence of Fresh Mortar (by Flow Table); European Committee for Standardization (CEN): Brussels, Belgium, 1999.

12. EN 1015-7. Methods of Test for Mortar for Masonry-Part 7: Determination of Air Content of Fresh Mortar; European Committee for Standardization (CEN): Brussels, Belgium, 1998.

13. EN 1015-6. Methods of Test for Mortar for Masonry-Part 6: Determination of Bulk Density of Fresh Mortar; European Committee for Standardization (CEN): Brussels, Belgium, 1998.

14. EN 1015-10. Methods of Test for Mortar for Masonry-Part 10: Determination of Dry Bulk Density of Hardened Mortar; European Committee for Standardization (CEN): Brussels, Belgium, 1999.

15. EN 1015-11. Methods of Test for Mortar for Masonry-Part 11: Determination of Flexural and Compressive Strength of Hardened Mortar; European Committee for Standardization (CEN): Brussels, Belgium, 1999.

16. EN 14146. Natural Stone Test Methods. Determination of the Dynamic Elastic Modulus of Elasticity (by Measuring the Fundamental Resonance Frequency); European Committee for Standardization (CEN): Brussels, Belgium, 2004.

17. EN 12504-4. Testing Concrete in Structures. Part 4: Determination of Ultrasonic Pulse Velocity; European Committee for Standardization (CEN): Brussels, Belgium, 2007.

18. EN 1015-18. Methods of Test for Mortar for Masonry-Part 18: Determination of Water Absorption Coefficient Due to Capillary Action of Hardened Mortar; European Committee for Standardization (CEN): Brussels, Belgium, 2002.

19. EN 1936. Natural Stone Test Methods. Determination of Real Density and Apparent Density and Total and Partial Open Porosity; European Committee for Standardization (CEN): Brussels, Belgium, 2007.

20. Cahier 2669-4. Certification CSTB des Enduits Monocouches D'imperméabilisation, Modalités D'essais; Centre Scientifique et Technique du Bâtiment: Marne-la-Vallée, French, 1993.

21. EN 1015-19. Methods of Test for Mortar for Masonry-Part 19: Determination of Water Vapour Permeability of Hardened Rendering and Plastering Mortars; European Committee for Standardization (CEN): Brussels, Belgium, 1998.

22. EN 1015-21. Methods of Test for Mortar for Masonry-Part 21: Determination of the Compatibility of One-Coat Rendering Mortars with Substrates; European Committee for Standardization (CEN): Brussels, Belgium, 2002.

23. EN 1015-12. Methods of Test for Mortar for Masonry-Part 12: Determination of Adhesive Strength of Hardened Rendering and Plastering Mortars on Substrates; European Committee for Standardization (CEN): Brussels, Belgium, 2000.

24. Filho, R.D.T.; Gonçalves, J.P.; Americano, B.B.; Fairbairn, E.M.R. Potential for use of crushed waste calcined-clay brick as a supplementary cementitious material in Brazil. Cem. Concr. Res. 2007, 37, 1357-1365. [CrossRef]

25. Kumavat, H.R.; Sonawane, Y.N. Feasibility Study of Partial Replacement of Cement and Sand in Mortar by Brick Waste Material. Environ. Sci. 2013, 4, 17-20.

26. Braga, M.; de Brito, J.; Veiga, R. Incorporation of fine concrete aggregates in mortars. Constr. Build. Mater. 2012, 36, 960-968. [CrossRef] 
27. Silva, J.; de Brito, J.; Veiga, R. Recycled red-clay ceramic construction and demolition waste for mortars production. J. Mater. Civil Eng. 2010, 22, 236-244. [CrossRef]

28. Angelim, R.; Angelim, S.; Carasek, H. Influence of the addiction of calcareous and clay fines on the properties of mortars and coatings. In Proceedings of the Brazilian Symposium on Mortars Technology (SBTA), São Paulo, Brasil, 11-13 June 2003; 2003; pp. 401-416.

29. Veiga, R. Behaviour of Renderings Mortars: Contribution for the Research in Cracking Resistance. Ph.D. Thesis, Civil Engineering, Faculty of Engineering of the University of Porto, Porto, Portugal, 1998. (In Portuguese). 